counter-irritation by blisters and sinapisms was had recourse to. The colchicum was exhibited in small doses of ten and fifteen minims in the first case, and of ten and five minims in the second, being continued in the latter in combination with ammonia, after the antimony had been given up. The doses of colchicum given in these cases, and especially in the second, were small. I have indeed long been generally in the practice of prescribing the remedy only in small doses, frequently repeated, with the view of preventing the occurrence of undue action on the stomach and bowels, and the consequent intolerance of the remedy. When exhibited in this form it exerts all its beneficial effects, and may be persevered in so long as the symptoms require its employment. I have before stated that the acute capillary bronchitis is not often seen as a sporadic affection, but most generally occurs as a complication of some form of epidemic disease. The combination with acute rheumatism, in which it was presented in the two cases which have been the subject of these lectures, is also far from common; indeed, the complication of acute rheumatism, unattended by any cardiac affection, with any form of acute bronchitis, is certainly rare; and it is well that it is so, for the complication adds very materially to the sufferings and danger of the patient, and may in some cases seriously embarrass the practitioner.

\section{ON THE CHEMICAL AND GENERAL EFFECTS OF THE PRACTICE OF INTERMENT IN VAULTS AND CATACOMBS.}

BY WALLER LEWIS, M.B. Cantab., F.G.S.

Much has been said and written on the decomposition of the human body after interment in the ordinary, and I may be allowed to call it, the natural mode-i. e., when buried in the earth. Very little, however, has been published on the process and results of such decomposition, when these are modified by the corpse being placed in a vault or catacomb. Even this little is incorrect in almost every important particular. I have been engaged for many months, in the years 1849 and 1850 , in inspectiog the greater part of the vaults of the churches of the metropolis for the General Board of Health; and as $I$ hope that in a short time the practice of entombment in receptacles of this kind will be prohibited, and the vaults themselves closed for ever, I consider it a matter of importance that some of the circumstances connected with these inquiries should be laid before the public.

Before the Report of the General Board of Health on Extramural Interments was laid before Parliament, the latest information we were in possession of was contained in a leading article in the Times newspaper, in the month of September, 1849. This was called forth by a regulation issued by the General Board of Health, during the prevalence of the late epidemic cholera. By this regulation, the authorities were enjoined not to allow any corpses to be placed in vanlts, except they were in "air-tight leaden coffins." The following sentences are extracted from this article:-

"It is a dismal duty, and one which we do not very willingly undertake, to descend into the gloomy abodes of the deadto make, so to speak, a show-box of the coffin, and to direct the public gaze on the shrouded slumberer within. It is, indeed, no beautiful spectacle, the so-called rest of a corpse after its soul has departed; and to observe how the dead man strives, after his fashion, to escape from his subterranean imprisonment with greater force than ever in life he could have exerted to tear asunder galling manacles, or burst through dungeon walls. These remarks may serve to explain the disapproval which we feel it our duty to express of an order just issued by the Board of Health, enjoining, as a condition of burial in intramural vaults, the use of air-tight leaden coffins. This order, manifesting, as it does, an inexplicable ignorance or disregard of the true objects and inevitable results of sepulture, requires at our hands a condemnation the more unqualified and explicit, as the previous measures of the Board, having been uniformly well-timed and judicious, may lend to this inconsiderate ordinance the prestige of a fallacious authority.

"Do the members of the Board of Health know what sort of substances they seek to confine, when they put a corpse weighing some eight or ten stone, into a box ' of sheet-lead closely soldered down?" Are they acquainted with the seventeen or eighteen chemical elements of which the human body is built up, and with the influence of confinement on the putrefactive combinations of these elements? Have they considered how, and by what process, that decomposition takes place, which leaves, at the end of ten years only, a few brittle bones in the else vacant shroud? And are they aware of the terrible retribution with which nature will punish the violation of her law, if they persist in obstructing with leaden barriers the corporeal absorption of the dead?"

"In the first place it is to be observed that the putrefaction of a corpse cannot be retarded by the exclusion of air and water from its subterranean receptacle. By withholding from the putrescent corpse a free supply of oxygen, we promote nay we positively cause, the formation of gaseous poisons so intense that their mere contact with a mucous surface of the body may occasion sudden death."

"The hydrogen of decaying flesh, which with a free supply of air would, by absorption of nitrogen, be chiefly converted into water, combines, within the airless coffin, with the sulphur of the hair and albumen, with the phosphorus of the bones and brain, and with the carbon of all the tissues, to form compounds all more or less noxious, and some of tremendous virulence. Among the products with which hydrogen thus combines is cyanogen, itself a compound of carbon and nitrogen, and which, with the addition of hydrogen, is converted into the terrible poison known as prussic acid; an agent so deadly, that one drop of it placed on the tongue suffices for the destruction of life."

"The pent-up gases first produced will exercise on the compounds subsequently formed, a pressure, the effect of which will be to change their composition and increase their virulence. The coffins will be bulged by the expansion of the elastic fluids generated under compression within; the acrid products of decomposition will gradually corrode the lead; and when, some few years hence, these horrible receptacles burst, the fumes emitted will destroy those who happen at the moment to be in their immediate vicinity, and will diffuse through our metropolitan atmosphere, the elements of a pestilence probably more virulent than that from which we are just emerging."

"We have really only two practical alternatives as to the disposal of the resulting gases-they must either be burned or breathed."

From the above extracts, it will be seen that the following assertions are brought forward:-

1. That among the products of decomposition are cyanogen, hydrocyanic acid, sulphuretted, carburetted, and phosphuretted hydrogen gases.

2. That all leaden coffins become bulged by the expansion of the elastic fluids within.

3. That the gases are pent up until the coffin becomes so corroded by them as to be unable any longer to confine them.

4. That the coffin then suddenly bursts, and the gases escaping, are capable of destroying all within reach.

5. That these effects take place within ten years.

6 . That the putrefaction of a corpse is not retarded by its being placed in an air-tight leaden coffin.

7. That the gases should be burned to destroy them.

Some of these allegations were so consonant with theory and common report, that one of the most eminent chemists in Europe, with whom I communicated on the subject, said that he "was not prepared to deny any one of them." He added, however, that he believed all the deductions were merely theoretical, as he knew of no experiments that had been made on the subject.

I therefore determined, with the sanction and approbation of the Board of Health, to ascertain, by actual experiment, every particular of the process of decomposition as effected in leaden and wooden coffins in vaults and catacombs, as well as for the purpose of keeping a record of the state, condition, and contents of these subterranean receptacles.

I have accordingly now carefully inspected between fifty and sixty vaults of the principal churches in London, and have examined the external condition and appearance of more than 22,000 coffins. I have also examined the state of the contents of nearly a hundred. The results of these investigations are so different from what could have been anticipated, and from what was generally believed to be the case, that I think it important to lay them before the profession, previous to the practice of interment in vaults becoming a matter of history.

$I$ may add that $I$ have not relied alone on my own researches, but have taken the evidence of all the clergy, churchwardens, sextons, and undertakers of every parish in which I could possibly obtain it. The following are some of the conclusions I have come to from these varied sources of information. It will be seen that they are all in direct contradiction to the allegations contained in the Times.

1. I have never succeeded in obtaining any traces of the 
presence of cyanogen, hydrocyanic acid, sulphuretted, phosphuretted, or carburetted hydrogen gases, even in the smallest quantity. In several instances $I$ analysed the air of the vaults themselves; and in one only, namely, in that of St. Mary-le-Strand, was there any indication of the presence of any of these. This was sulphuretted hydrogen in a very minute proportion, and there was no certainty of this being derived from the decomposing bodies, which are here only thirty-two in number. I examined gases formed by bodies of persons of all ages, from the still-born infant to those who had survived to the age of ninety-two. The coffins had been in the vaults various lengths of time; those that had been there a week were examined, as well as those that had remained there a century and a half. Death had been caused by accident, by age, by disease. The latter had been of the most varied kinds-typhus, phthisis, small-pox, childbirth, dropsy, and cholera.

Not one of the above circumstances seemed to influence, in the slightest degree, the composition or character of the gases. 'These were most remarkably similar in every instance. All the gases $I$ analysed or otherwise examined were composed of nitrogen and carbonic acid gas, mixed with atmospheric air, and holding decaying animal matter in suspension. There was but one ingredient that was sometimes present, sometimes entirely absent: this was ammoniacal gas, which was sometimes present in very large quantities. When this was added to the other gases, it overcame all other odour; when it was absent, the smell much resembled that of very putrid moist cheese. In every instance I searched most carefully for the presence of the hydrogenous gases mentioned, but never found the slightest traee of any one of them.

Another proof, if any were wanting, of the absence of sulphur in any considerable quantity as a product of decomposition, is, that although the metal of many of the older coffins had been acted upon, the substance thus formed was always a carbonate, never a sulphuret or sulphate of lead.

2. All coffins do not become bulged by the expansion of the elastic fluids within. On the contrary, so rarely is this the case, that it is the exception instead of the rule. In many vaults there was no instance of a coffin that had bulged, or, as the undertakers say, "blown." In 22,000 I could not find 20 that were or had been in this condition. This is to be accounted for by the fact that lead is so porous a metal that it allows the exosmose or transudation of the gases with great facility, more especially when there is pressure within. It is well known that even the iron gas pipes so thickly underlying our pavements cannot be made retentive of the gas.

3. The gases, therefore, are but very rarely pent up; the instances of "blown" coffins not averaging one in a thousand.

4. The coffin does not suddenly burst, and the escaping gases do not desiroy all within reach. From the most searching inquiries from coffin-makers, undertakers, and all persons most likely to be well informed on the subject, I have never obtained any sufficient evidence of the sudden rupture of a coffin. It is universally the custom of sextons, when they perceive any leaden coffin to be blown, to send to the undertaker for the purpose of having a hole drilled in the upper part of the lead, so as thus to allow the escape of the foul air. During the operation, the parties employed endeavour to avoid inhaling the gas, and sometimes hold a piece of burning wood or paper at the orifice, so as to destroy in some measure the offensive odour I have described. In my opinion, the fact that coffins so rarely become bulged, is to be ascribed to the great porosity of the metal employed. When slightly bulged, the lead, from being thinner than before, becomes more pervious to the contained air.

The action of the putrefactive gases on the human frame, although not so immediately fatal as the Times would have us believe, certainly produces many disagreeable symptoms. In my own person, the most prominent among these were nausea, with vomiting, after continued exposure, succeeded by diarrhea. These are followed on the succeeding day by a throbbing pain in the upper part of the head, great prostration, and entire loss of appetite, accompanied with an unpleasant earthy taste in the mouth. These symptoms, after being experienced for a long time, were followed by a scries of boils, accompanied with much phlegmonous erysipelas, and requiring surgical assistance.

On one occasion, however, I was nearly meeting with an exception that would have corroborated, to a certain extent, the assertion that sudaden death may occur from such exposure. I was examining the large vault under the church of St. Andrew's, Holborn, which contains about five thousand coffins, partly of wood, partly of lead. They are placed in eight arched culs-de-sac running off on either side of the central passage. The air in these compartments is in a state of almost complote stagnation, as there is no ventilation in them. The coffins are piled one above another from ten to thirteen high, and reach to within a short distance of the roof. There is scarcely sufficient room to allow a man to crawl on all fours between the upper coffins and the bricks of the arches. Wishing to see how far these compartments filled with coffins extended, I sent the sexton in with a candle. In a very short time, observing the flame begin to lower, and give very little light, I called to the man to come out immediately. He instantly obeyed, and after much exertion and the extinction of the candle, he presented himself in a pitiable condition, his eyes half starting from their orbits, breathing deeply, and evidently much oppressed. Exposure to a current of fresh air shortly revived him. The air being mixed with a large quantity of carbonic acid gas was the cause of this nearly fatal accident-not the presence of cyanogen of any hydrogenous compound.

5 . The complete decomposition of a corpse, and its resolntion into its ultimate elements, is by no means accomplished in a period of ten years; nor is that description accurate which represeuts, that at the end of that period nothing "but a few brittle bones are left in the else vacant shroud." On the contrary, so extremely slow is the process under the circum. stances, that $I$ have but rarely seen the remains in a leaden coffin of any age in the condition described. In a wooden coffin, the remains are found exactly in this state in a period of from two to five years. This period depends upon the quality of the wood, and the free access of air to the coffin. But in leaden coffins, fifty, sixty, eighty, and even a hundred years, are required to accomplish this. I have opened a coffin, in which the corpse had been placed for nearly a century, and the ammoniacal gas formed dense white fumes, when brought into contact with hydrochloric acid gas, and was so powerful that the head could not remain near it for more than a few seconds at a time.

6. The putrefaction, therefore, is very much retarded by the corpse being placed in a leaden coffin.

7 . If by this assertion it is only meant that the gases should be passed through flame, to destroy the organic particles mixed so largely with them, this can be understood. This difficulty would, however, still remain: except in the fer exceptions I have mentioned of blown coffins, the gases are so slowly generated, that no force would be exerted from within sufficiently powerful to expel them. But if it is assumed that these gases can be inflamed like coal gas, I must deny the possibility of this. I tested the gaseous contents of nearly a hundred coffins, some of which contained a considerable quantity of gas. In no one instance would the gas inflame; on the contrary, in every instance, it extinguished the flame. In addition to my own experiments, I made the most minute inquiries of churchwardens, clerks, undertakers, and sextons, but I have never met with any person who has actually seen coffin-gas inflame. Several have told me that they have heard that it does, but they did not know the fact from their own experience. Some of the officials of St. Anme's, Soho, pointed out a coffin to me, which, having some years ago become blown, had been "tapped." They asserted that a long blue flame had been obtained by firing the jet of gas which issued from the aperture: The smell was described as that of sulphuretted hydrogen; but not one of these persons was present at the time. If, therefore, this or any other hydrogenous compound is ever formed as a result of such decomposition, it is an extremely rare exception.

The following are the conclusions $I$ have arrived at from these investigations:-

1. Interment in vaults and catacombs should no longer be permitted. No good object is gained by this practice. The corpses so treated are by this means converted into so many active volcanos, constantly emitting poisonous effluvia into the atmosphere, for an indefinite period.

2. That after a certain interval, during which friends or relatives should have the power of removing any coffin from the vaults to the public cemeteries, all these receptacles shoul be hermeticaliy closed, and future access thereto forbidden.

3. The use of leaden coffins should be entirely discontinued: they only add to the already exorbitant charges of undertakers. Until a very late period they were constantly stolen from the vaults, emptied of their contents, and sold as old lead. 4. If the object of interment is to allow the liuman body, after it has served its purpose here, to return as speedily as possible to its elements, and to become perfectly inert, it should be placed in a light wooden coffin, from five to eight feet deep, in a suitable pervious soil. 